\title{
Interculturalidad en el marco normativo de la educación física en Colombia. Introito a la formación profesiona*
}

\author{
ARNULFO HURTADO CERÓN** \\ VÍCTOR ALONSO MOLINA BEDOYA**
}

Universidad de Antioquia - Colombia

Recibido el 26-09-2017; primera evaluación el 16-01-2019; segunda evaluación el 03-02-2019; tercera evaluación el 24-02-2019; aceptado el 28-02-2019

\section{RESUMEN}

El artículo expone los resultados de la investigación: interculturalidad y cultura de los pueblos indígenas en los procesos de formación profesional en Educación Física en Colombia, que tuvo como propósito reconocer la presencia o ausencia de la diversidad en los currículos de los programas existentes con registro activo en el Sistema Nacional de Información de la Educación Superior del país. Metodológicamente se abordó desde un diálogo entre el caminar la espiral — Jijunan (comprensión) y la Kajijunan (interpretación) — propia de los pueblos indígenas de la nación y la técnica de análisis de contenido; desde la cual se buscó inferir y dar a conocer lo latente en los documentos institucionales de las universidades con cursos en el campo. Se encontró poca presencia de estas categorías en los currículos de los programas vigentes en Colombia.

Palabras clave: Educación física, diferencias, integración cultural, legislación educativa (IRESIE).

\footnotetext{
* Resultado de la investigación: interculturalidad y cultura de los pueblos indígenas en los procesos de formación en Educación Física en Colombia, correspondiente al primer momento de análisis del marco normativo. Pesquisa realizada en la Maestría Motricidad- Desarrollo Humano de la Universidad de Antioquia, adscrita a la línea de Ocio y pensamiento crítico latinoamericano.

"Profesor catedrático de la Universidad de Antioquia. Líder e integrante del grupo de investigación Ocio, expresiones motrices y sociedad. Coordinador del semillero de investigación GOCEMOS. Magíster en Motricidad-Desarrollo Humano y licenciado en Educación Física de la Universidad de Antioquia. Teléfono: 5742199267. Correo: arnulfo.hurtado@udea.edu.co

"*t Profesor titular de la Universidad de Antioquia. Posdoctor por la Universidad Federal de Minas Gerais de Brasil. Doctor por la Universidad de Valladolid, Espańa. Magíster en Salud Colectiva y licenciado en Educación Física de la Universidad de Antioquia. Especialista en Cultura Política de la UNAULA. Par evaluador de Colciencias - Colombia. Teléfono: 5742199267. Correo: victor.molina@udea.edu.co
} 
Interculturality in the normative framework of physical education in Colombia. Introitus to professional training

\section{AbSTRACT}

This article presents the results of the research Interculturality and culture of indigenous peoples in the professional training process in Physical Education in Colombia; which aimed to recognize the presence or absence of diversity in the curricula of existing programs with active registration in the National Higher Education Information System of the country. It was approached methodologically from a dialogue between walking the spiral - Jijunan (understanding) and Kajijunan (interpretation) - proper of Colombian indigenous peoples and the content analysis technique; from which it aimed to infer and uncover what is latent in institutional documents of universities with courses in the field. There was little presence of these categories in the curricula of the current programs in Colombia.

Keywords: Physical education, differences, cultural integration, educational legislation (IRESIE).

Interculturalidade no marco normativo da educaçáo física na Colômbia. Introdução à formaçáo profissional

RESUMO

$\mathrm{O}$ artigo apresenta os resultados da pesquisa: Interculturalidade e cultura dos povoados indígenas no processo de formação profissional em Educação física na Colômbia, que teve como propósito reconhecer a presença ou ausência da diversidade nos currículos dos programas que existem com registro ativo no Sistema Nacional de Informação da Educação Superior do país. Metodologicamente se abordou desde um diálogo entre o caminhar a espiral - Jijunan (compreensão) e a Kajijunan (interpretação) - própria dos povoados indígenas da nação e a técnica de análise de conteúdo; desde a qual se procurou deduzir e desvendar o latente nos documentos institucionais das universidades com cursos no campo. Encontrou-se pouca presença destas categorias nos currículos dos programas vigentes na Colômbia.

Palavras-chave: Educação física, diferenças, integração cultural, legislação educacional (IRESIE). 


\title{
1. INTRODUCCIÓN
}

\author{
Como la Gaitana \\ en un acto de sagrada altivez, \\ reivindicaba desde estas \\ comarcas las cenizas de su hijo \\ arrojadas al viento. Asi la raza, \\ al pie de un continente, al \\ pie de este simbolo levantado \\ como un juramento, reafirma \\ en su esencia y atributos una \\ nueva y solidaridad conciencia \\ americana. \\ David González
}

La interculturalidad, el multiculturalismo y la transculturalidad ganan cada vez mayor presencia en los debates académicos y sociales al interior de la sociedad colombiana, como expresión de un interés creciente por afianzar el carácter diverso del país y por favorecer procesos de convivencia más respetuosos de las diferencias, es decir, más democráticos.

De forma especial, con el ejercicio, se buscó problematizar la relación formación superior e interculturalidad; línea que adquiere relevancia para un país que se reconoce multicultural y pluriétnico, pero que en su cotidianidad se debate en prácticas y comportamientos coloniales que acentúan, y son marcados a la vez, por condiciones de inequidad y desigualdad con mayor impacto para determinados grupos de la sociedad. Al decir de López (2004), las condiciones de inequidad y desigualdad social determinan las relaciones entre indígenas y no indígenas.

En tal horizonte, este ejercicio investigativo parte desde el enraizamiento del ombligo en la madre tierra, y el caminar en la espiral que ha desenvuelto la vida, Jijuna (comprendiendo) Kajijuna (interpretando) la realidad sociohistórica que ha conllevado a indagar y problematizar los acaeceres, que han tocado la cultura de los pueblos indígenas y la interculturalidad en los procesos de formación profesional en el campo de la Educación Física en el país. En tal sentido, el caminar en la espiral se dispuso en la horizontalidad del diálogo (Corona y Kaltmeier, 2012) con la técnica del análisis de contenido, para inferir, desvelar lo latente, lo no aparente (Bardin, 1986) en los documentos institucionales y mallas curriculares de las universidades que ofertan programas de formación profesional en el área en Colombia, tanto del nivel de pregrado como de posgrado.

La pregunta que orientó la investigación fue: ¿Cómo se aborda la cultura de los pueblos indígenas y la interculturalidad en los procesos de formación 
profesional en el campo de la Educación Física en Colombia?, como preguntas subordinadas: ¿Cómo se articulan los direccionamientos que, en materia de interculturalidad, traza tanto el Ministerio de Educación Nacional (MEN) como la política pública educativa del país, ¿Cuál es la presencia de la interculturalidad y la cultura de los pueblos indígenas en los procesos de formación profesional en Educación Física? ¿Cuáles son las estrategias implementadas en los currículos de formación profesional en Educación Física para abordar la diversidad social y cultural del país?

Entre las razones que justificaron la realización del ejercicio se destaca, en primer lugar, que desde la maestría Motricidad y Desarrollo Humano se tracen posibles rutas de investigación que aborden lo social desde la diversidad, la culturalidad e interculturalidad y desde el valioso conocimiento cosmogónico que poseen los pueblos indígenas de la nación colombiana.

En segundo lugar, resultaría un gran aporte para las universidades que ofertan programas de educación superior conocer-reconocer la diversidad cultural, pues daría luces para la generación de procesos más compartidos con las comunidades originarias, teniendo en cuenta que cada pueblo tiene su cosmovisión y conocimientos ancestrales que pueden ser de gran aporte para el campo de la Educación Física en lo particular.

En tercer lugar, la cultura de los pueblos indígenas y la interculturalidad es de suma importancia en los recintos educativos, ya que serían claves para la construcción de un tejido social basado en el diálogo compartido desde los saberes cosmogónicos de cada comunidad indígena con los compańeros mestizos de las ciudades, pues es evidente, en muchos de los casos, el desconocimiento de la existencia de la diversidad cultural en Colombia. Es necesario introducir políticas que pongan en diálogo la interculturalidad para una sociedad más justa y compartida desde las diferentes epistemologías.

Como categorías centrales del estudio, se tuvieron: cultura, interculturalidad y formación profesional en educación física. Por cultura se entendió el conjunto de esquemas, conductas, costumbres, usanzas, tradiciones y hábitos que yacen en el proceso histórico de las expresiones del hombre (Geertz, 1989).

Por interculturalidad se comprendió el proceso de diálogo entre las culturas que, significativamente, trasciende la pluriculturalidad y la multiculturalidad, ya que desde ella se promueve la comunicación, el encuentro entre culturas para contrastar, aprender y resolver conflictos recíprocamente. Es una noción que aboga por la defensa de la diversidad y que implica reconocimiento y comprensión de otras culturas desde el respeto, comunicación e integración (Villodre y Del Mar, 2012). 
Por último, la formación profesional en Educación Física se entendió como el proceso por el cual un individuo se capacita en el campo de conocimiento específico para desenvolverse en temas de interés empírico, técnico y científico para el saber y el hacer. Metodológicamente en diferentes contextos sociales desde habilidades comunicativas, de interacción, toma de decisiones y asunción de responsabilidades sociales (Maura y Tirados, 2008).

Es propósito de este artículo presentar los resultados relativos al análisis de los textos oficiales que regulan la actuación de la educación física a nivel nacional, no obstante, se consideró importante presentar la ruta metodológica de la investigación de la cual se derivó el material que aquí se expone. Momento determinante para poder tener una comprensión amplia, de la forma como esos documentos dialogan con la formación en el campo.

\section{ACAECERES DE LA REALIDAD SOCIOHISTÓRICA DE LA EDUCACIÓN EN Colombia}

Actualmente en el país existen 87 pueblos indígenas, ubicados en diferentes sitios de la geografía nacional con 64 lenguas, descendientes de los Chibchas, Caribe y Arawak (Castro, 2010).

La Constitución Política de Colombia (1991) reconoce importantes derechos a los pueblos indígenas, entre los que se encuentran: el reconocimiento a la diversidad étnica y cultural (artículo 7), las lenguas y dialectos como oficiales en los territorios de los grupos étnicos que deben ser promulgados como la enseñanza bilingüe en las comunidades con tradiciones lingüísticas propias (artículo 10), y el derecho a una formación que respete y desarrolle su identidad cultural (artículo 68).

No obstante este mandato, aún es incipiente la idea de unas relaciones sociales basadas en la interculturalidad y el respeto, como posibilidad de los diferentes pueblos indígenas de entretejer y vivir un saber u otro, una epistemología u otra, una experiencia política u otra, un gobierno propio desde las leyes de origen; un pensamiento que reivindique las raíces de las culturas tejido en los principios éticos, políticos y económicos que apunten a la descolonización de las formas de vida de los pueblos (Molina-Bedoya, 2012).

Los pueblos indígenas aún siguen luchando por el conocimiento-reconocimiento de sus culturas, impulsando activamente procesos de intercambio que permitan construir espacios de encuentro entre seres y saberes, sentidos y prácticas diferentes (Sánchez, Enrique, Benjumea, Rodríguez y Nieto, 2003); trenzando diálogos y cosmovisiones desde la educación, lo que en muchos casos ha resultado infructuoso, pues socialmente se desconoce la existencia 
de los pueblos aborígenes, razón del avasallamiento colonial que se expresa en acciones represivas y de despojo de los sitios sagrados por parte de las multinacionales, en muchos de los casos, con la anuencia del Estado colombiano.

\section{Metodología}

La investigación se fundamentó en el desenvolver de la espiral ${ }^{1}$, buscando la Jijunan (comprensión) Kajijunan (interpretación) de la realidad y las situaciones sociales-culturales referidas a la cultura de los pueblos indígenas y la interculturalidad en los escenarios de las instituciones públicas y privadas de educación superior y en el marco normativo que emana del Estado, a partir de un diálogo horizontal (Corona y Kaltmeier, 2012) con la técnica del análisis de contenido para inferir, desocultar lo latente, lo no aparente (Bardin,1986) en los documentos institucionales y mallas curriculares de las universidades de Colombia.

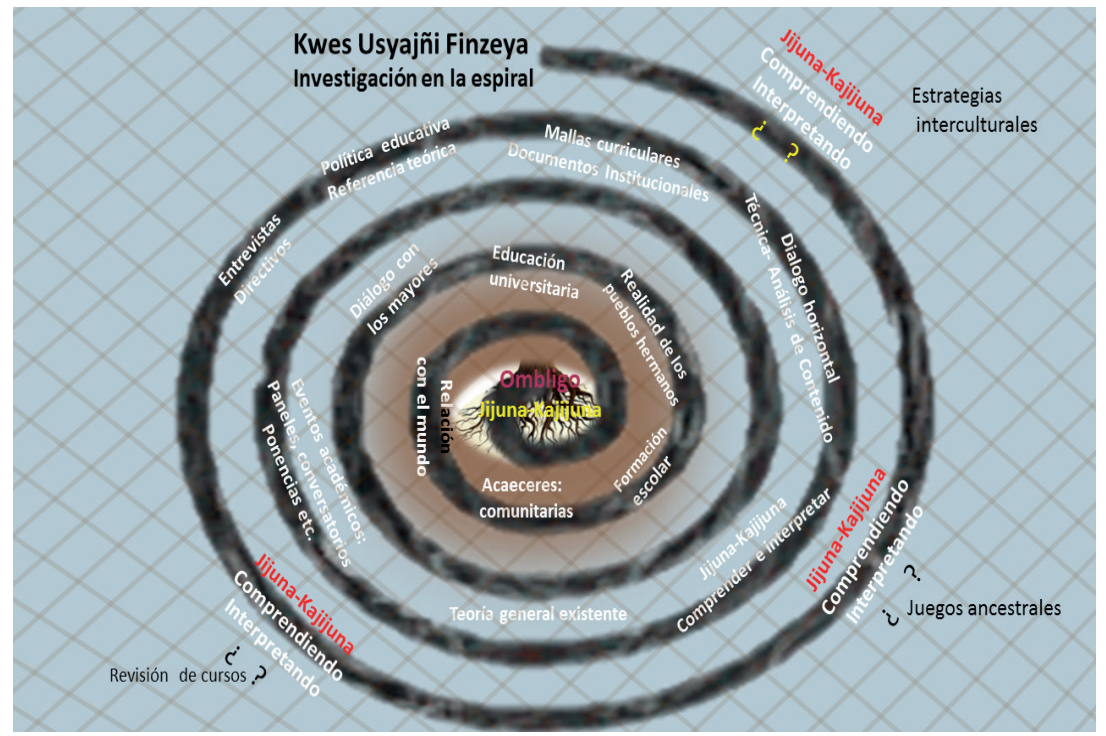

Grafico 1. Kwes Usyajñi Finzeya (Investigación en la espiral).

1 La espiral representa el desenvolvimiento de la existencia del pueblo nasa. Pensamiento circular que nos permite avanzar y estar retornando al origen. Así, el ombligo inicia a tejer la vida conectada con la madre tierra interpretando y comprendiendo el mundo. Se aborda esta perspectiva cosmogónica pues uno de los autores es miembro de esta comunidad indígena. 
El análisis de contenido se concibe como el conjunto de mecanismos capaces de generar interrogantes, y no como una fórmula para obtener respuestas. «Dicho de otro modo, ha de concebirse como un procedimiento destinado a desestabilizar la inteligibilidad inmediata de la superficie textual, mostrando sus aspectos no directamente intuibles y, sin embargo, presentes» (Delgado, 1998, p.182).

Como técnica investigativa, el análisis de contenido se ocupa de las expresiones verbales consignadas en los textos, pero en esencia no se remite a ellos en sí mismos, sino a algo en relación con lo cual estos funcionan en cierto modo como instrumento, para centrarse propiamente en el análisis de lo contenido fuera de ellos.

Para Ruiz (1999), consiste en una técnica que permite inferir del texto características personales, sociales, culturales e ideológicas, deduciendo del texto su contexto, siendo la inferencia el elemento central del análisis de contenido, diferente al análisis documental que se limita estrictamente al contenido del texto mismo.

La estrategia de análisis fue extensiva, es decir, se trabajó con un corpus relativamente amplio representado por las mallas y los documentos institucionales elaborados por diversos autores e instituciones. La estrategia intertextual que se privilegió fue la del método discriminatorio, desde la cual se conformaron conjuntos de textos según las fuentes de producción, para el caso, política pública educativa, páginas virtuales de las universidades y plataforma SNIES del MEN.

De acuerdo con el objetivo de la investigación, el corpus de análisis estuvo integrado por documentos institucionales referidos a los programas de formación superior en Educación Física, relativos a los niveles de licenciaturas, profesionalizaciones y posgrados actualmente existentes en Colombia, los cuales fueron ubicados en las páginas virtuales de las universidades e instituciones universitarias tanto públicas como privadas, que contaran con registro activo en la plataforma Sistema Nacional de Información de la Educación Superior (SNIES) del Ministerio de Educación Nacional, a la fecha de recopilación de los textos.

Durante el proceso de filtración y constatación de los programas en el SNIES, se encontró con registro activo 46 mallas curriculares del nivel de pregrado, entre licenciaturas y profesionalizaciones. Para el caso de los posgrados, se ubicó 8 maestrías y 10 especializaciones. Sin embargo, se aclara que tres especializaciones que aparecieron con registro activo en el SNIES de la Universidad Pedagógica Nacional no pudieron ser ubicadas virtualmente, por ello se contactó con la institución y se informó que no se estaban ofertando en el momento. 
Con este conjunto de documentos, se procedió a la fase de análisis, que consistió en un primer mapeo - lectura fluctuante- o representación general a partir de la organización de bancos de datos. Esto implicó una aproximación genérica a los documentos con el fin de tener impresiones generales sobre la información que allí se encontraba.

Para la fase de análisis se consideró como unidades básicas de relevancia, la interculturalidad y la cultura de los pueblos indígenas. Estas unidades representan para Delgado (1998) las unidades de registro.

Para avanzar en el nivel de significación, las unidades de registro se localizaron en las unidades de contexto y fueron relacionadas con la información extratextual. De aquí se pasó a la fase de codificación, en la cual las unidades de registro encontradas en los documentos fueron relacionadas con sus respectivas unidades de contexto.

Respecto a las consideraciones éticas de la investigación, se obtuvo consentimiento informado de las personas que participaron en el estudio, igualmente se garantizó y preservó el anonimato de los participantes como sujeto de derechos. En la obtención de los documentos públicos: textos institucionales y mallas curriculares, la investigación se guio por lo dispuesto en la ley 1712 (2014), que consagra derecho de acceso a la información para quien lo requiera.

Ahora bien, hasta aquí esta es la metodología que se abordó para dar cuenta de los objetivos generales de la investigación, de acuerdo con los propósitos del artículo que aquí se presenta, se realizó un análisis cruzado de los documentos normativos que regulan la actuación del campo de la Educación Física, Recreación y Deporte en el país, tales como: ley del deporte, serie de lineamientos curriculares, plan decenal de la Educación Física y orientaciones pedagógicas.

Estos documentos fueron abordados desde el análisis documental que, como proceso analítico-sintético, se intencionó por la construcción de un nuevo texto erigido sobre la base de examinar la presencia o ausencia de la interculturalidad en esta normatividad oficial; lo que implicó: una ubicación de los materiales, un análisis formal y un análisis interno desde el referente de la diversidad cultural.

\section{Resultados y discusión. Normatividad, Educación Física e INTERCULTURALIDAD}

En este acápite se aborda la normativa de la educación colombiana desde los mandatos constitucionales y las leyes, tales como: la ley 115 de 1994, ley 30 de 1992, ley 397 de 1997 y la ley 181 de 1995 (normativa específica del deporte 
y la recreación en país), para analizar las presencias y las ausencias de la cultura de los pueblos indígenas, la interculturalidad, el buen vivir y la forma como interaccionan como política pública en los procesos de formación profesional en Educación Física.

La Constitución Política de Colombia (CPC, 1991), como norma de normas que rige al conjunto de la sociedad colombiana, respecto al tema de la cultura y la interculturalidad, en sus artículos 7, 8, 10 y 13 declara la obligación del Estado y de las personas de resguardar la riqueza sociocultural, respetar la cosmovisión, las prácticas ancestrales y el idioma de cada pueblo. Sobre este particular declara que al igual que el castellano, las demás lenguas son también oficiales del país.

El artículo 13 protege la libertad de las personas desde su nacimiento, la igualdad en el goce de los derechos sin discriminación de raza, origen, lengua, religión, filosofía, entre otros, y declara que es el Estado el encargado de promover la igualdad real y las relaciones socioculturales sin exclusión y subalternización (Constitución Política de Colombia, 1991).

También se encuentran mandatos en la CPC referentes a la organización de los territorios indígenas, donde destaca la figura de los resguardos como entidades territoriales especiales según artículo 286 y 329. Así mismo señala que los territorios nativos son propiedad colectiva inenajenables e inembargables, y su reglamentación estará orientada mediante usos y costumbres de cada comunidad de acuerdo con los artículos 63 y 330. De igual forma el artículo 72 afirma que el patrimonio cultural arqueológico que se encuentre en los asentamientos de los pueblos originarios es propiedad de la nación y se le otorgará, mediante reglamento especial, los derechos que les conciernan a los pueblos indígenas (Constitución Política de Colombia, 1991).

Respecto al tema educativo, la CPC en su artículo 67 afirma que la educación es un derecho de la persona y un servicio público, que tiene como función social formar al colombiano en el respeto a los derechos humanos, a la paz, a la democracia, a la práctica del trabajo y la recreación para el mejoramiento sociocultural. Igualmente, en el artículo 68 y 70 determina para los pueblos indígenas, educación de acuerdo a su cultura, promoviendo y fomentando el acceso de todos los nacionales en igualdad de oportunidades (Constitución Política de Colombia, 1991).

En este orden, la Ley General de Educación, en el artículo 1, de la garantía a la prestación del servicio educativo desde los niveles preescolar, básica primaria y secundaria - media no formal e informal—, establece la educación como un derecho sin discriminación para los pueblos campesinos y grupos étnicos existentes. Los medios masivos de comunicación deben promover la riqueza 
artística y cultural que compone la sociedad colombiana, según el artículo 45 (Ley 115, 1994).

Asimismo, el artículo 5 proclama que los procesos formativos se deben basar en el respeto por el pluralismo, la cultura nacional, y la reivindicación de los valores de la diversidad étnica, fomentando la enseñanza obligatoria de la identidad cultural en los escenarios educativos, tanto públicos como privados. Del mismo modo, consagra en el artículo 14, la incidencia en el aprovechamiento del tiempo libre, la Educación Física y el deporte formativo sin desmedro de la diversidad cultural (Ley 115, 1994).

Esta ordenanza legisla en pro del fortalecimiento cultural de los pueblos indígenas como precisa en el artículo 21a y b, la promoción de procesos formativos para la convivencia social, democrática, participativa y pluralista, garantizando la conservación y el desarrollo de las habilidades comunicativas de los idiomas propios de los pueblos étnicos. El artículo 23, despliega el plan de estudio de la educación básica conformado por las áreas de: ciencias naturales y educación ambiental, ciencias sociales; historia; geografía; constitución política y democracia, educación artística, educación ética y en valores humanos, educación física, recreación y deportes, educación religiosa, humanidades, lengua castellana e idiomas extranjeros, matemáticas, tecnología e informática. En la designación de la educación básica, no hay ninguna asignatura que dé cuenta de la diversidad cultural del país, por tal situación se puede intuir que los temas socioculturales se estén asumiendo como ejes transversales de las áreas que implanta esta ley, y que si bien, la transversalidad en los procesos educativos podrá ser posible si se tiene conciencia crítica de la realidad histórica, y del presente que siguen resistiendo los pueblos originarios del Abyayala.

En este mismo mandato se puede encontrar, en el artículo 56 y 57 lineamientos específicos que orientan la educación para los grupos étnicos desde los principios y fines generales fundamentados en la integridad de la interculturalidad, diversidad lingüística, participación comunitaria, flexibilidad y progresividad, en aras de afianzar los procesos de identidad, conocimiento, socialización, protección y usos adecuados de la naturaleza, sistemas y prácticas comunitarias de organización, uso y enseñanza de las lenguas nativas tomando como fundamento escolar la lengua materna de cada comunidad.

Se señala, en los artículos 55, 58, 59, 60, 61, 62 y 63 de esta misma ley, que el Estado proveerá y fomentará la formación de educadores de la misma comunidad, del mismo modo establece, que serán las autoridades indígenas quienes seleccionarán sus educadores para su contexto educativo. Así, el Estado solo prestará asesoría especializada a través del Ministerio de Educación Nacional 
siempre concertada con los pueblos indígenas para el desarrollo de guías curriculares, construcción de textos, materiales educativos y ejecución de programas de investigación y capacitación etnolingüística para el fortalecimiento cultural. Establece también que los organismos internacionales no podrán incidir en las comunidades sin la aprobación del Ministerio de Educación Nacional y la colectividad étnica (Ley 115, 1994).

El capítulo 3 de la ley, da cuenta la composición de las juntas y foros de educación, organizados desde el más general, Junta Nacional de Educación (JUNE) que actúa como órgano científico y con carácter de consultor permanente del MEN para la planeación y diseño de las políticas públicas del Estado, y que está integrado por servidores públicos tales como: quien presida el MEN, un delegado territorial departamental, distrital, municipal, 2 investigadores del campo educativo entre otros.

Por otra parte, en el mandato de la educación superior -la Ley de Servicio Público de la Educación Superior (Ley 30 de 1992), en especial, sus artículos 2 y 4 da cuenta de la educación superior como un servicio público, cultural y esencial a la finalidad social del Estado, y se orienta al logro de la autonomía personal, la libertad de pensamiento y a la preservación de los saberes de las culturales existentes en el país, como se afirma en el artículo $6^{\circ}$ de la Constitución Nacional (Ley 30, 1992).

Sin embargo, aunque en esta ley hay referencia a la diversidad cultural presente en la geografía nacional, no es clara la manera cómo se van a asumir las culturas aborígenes en las instituciones de educación superior, ya que solo las menciona, pero no estipula cómo se va a generar una relación de reciprocidad entre epistemologías propias de los pueblos indígenas y las epistemologías tradicionales eurocéntricas.

De igual manera, hay que resaltar lo enunciado en su título 2 respecto al Consejo Nacional de Educación Superior (CESU) y al Instituto Colombiano para el Fomento de la Educación Superior (ICFES), los cuales están conformados por: el MEN o delegado, ministro de Hacienda, delegado de la presidencia de la república, exrector de la universidad estatal u oficial y privada, y no se contempla en esta ordenanza, delegados de los pueblos étnicos que represente sus derechos.

De otra parte, la Ley General de Cultura (Ley 397 de 1997) concibe la cultura como el conjunto de rasgos, distintivos, valores, tradiciones, creencias y espiritualidades que determinan a los grupos humanos y los modos de vida de los pueblos en sus diversas manifestaciones culturales. Indica que es deber del Estado impulsar los procesos, proyectos y actividades culturales en el marco del conocimiento-reconocimiento y respeto por la diversidad, sin censurar la 
forma y el contenido ideológico y artístico, por el contrario, debe valorar, proteger y difundir el patrimonio cultural de los grupos étnico-lingüísticos, de las comunidades negras, raizales y de los pueblos indígenas garantizándoles una educación que beneficie el derecho propio de cada cultura, según el artículo 1 de los principios fundamentales y definiciones de esta ley (Ley 397, 1997).

Igualmente, esta ley ratifica que las lenguas de las comunidades negras, raizales e indígenas son reconocidas como patrimonio de la cultura y serán fortalecidas y respetadas en la sociedad, al igual que las lenguas criollas habladas en el territorio nacional. Idiomas que se valorarán como derechos de los pueblos a la convivencia, la solidaridad, la interculturalidad, el pluralismo y el respeto como base fundamental para una cultura de paz.

Asimismo, el artículo 2 define como papel del Estado preservar el patrimonio cultural y promover las expresiones artísticas de los ámbitos locales, regionales y nacionales en coordinación con el Ministerio de Cultura, de acuerdo con el plan nacional de desarrollo. Establece, igualmente, que el patrimonio cultural de la Nación se constituye de valores, tradiciones, costumbres, hábitos, bienes inmateriales y materiales, muebles e inmuebles de interés histórico, artístico, estético, plástico arquitectónico, arqueológico, ambiental, lingüístico, musical, literario, antropológico y de todas las representaciones de la cultura popular, artículo 4 (Ley 397, 1997).

En el marco administrativo, establece esta Ley, en relación con el patrimonio cultural, que será direccionado por el Ministerio de Cultura como organismo rector, encargado de formular, coordinar, ejecutar y vigilar la política del Estado en la materia, en concordancia con los planes y programas de desarrollo, según los principios de participación que contempla este mandato. A su vez, observa en el artículo 7 del Concejo Nacional de Patrimonio Cultural, que es el órgano encargado de asesorar al gobierno nacional en todos los temas relacionados con la salvaguardia, protección y manejo de la riqueza cultural, cuya estructura está integrada por el Ministro de Cultura, Ministro de Comercio, Industria y Turismo, Ministro de Ambiente, el Decano de la facultad de Artes de la Universidad Nacional de Colombia, el Director del Instituto Colombiano de Antropología e Historia y otros.

En otro apartado, centrándonos en la normatividad específica del deporte, la recreación, el aprovechamiento del tiempo libre y la Educación Física en Colombia, se dispone, en la Ley 181 de 1995, que el ejercicio del deporte, sus manifestaciones recreativas, competitivas y autóctonas tienen como función la formación integral de las personas, preservando y desarrollando una mejor salud, según el artículo 1 . También en su artículo 3 dice que desde el deporte 
y la recreación se deben favorecer las expresiones culturales, folclóricas o tradicionales desde las fiestas típicas, que se arraigan en el territorio nacional. Estas prácticas deberán ser apoyadas de manera especial, diseñando programas formativos y de competición para la promoción del deporte y la recreación en las comunidades indígenas a nivel local, regional y nacional, como un gesto de participación democrático-pluricultural, que reivindique la recreación, el ocio, el tiempo libre y el juego, desde la cosmogonía de cada pueblo, sin discriminación alguna de raza, credo, condición o sexo, artículos 4 y 25 de la Ley 181 de 1995.

Por su parte, la serie Lineamientos curriculares, Educación Física, Recreación y Deporte denota en sus apartados la promoción del conocimiento de la diversidad y la pluriculturalidad, así como los factores socioculturales de los procesos curriculares de este campo, fomentando y refortaleciendo las varias prácticas lúdicas milenarias y propias, de ocio, recreación y deportivas de cada pueblo indígena para socializarlas y entablar un diálogo entre las culturas de la nación (MEN, 2000, p. 20).

Es contundente el capítulo 3 de esta serie, alusivo a los referentes socioculturales, al establecer que: «El currículo en Educación Física debe partir del reconocimiento de la diversidad, atendiendo las diferencias, pero sin establecer discriminaciones ni separaciones» (MEN, 2000, p. 20). Según este fragmento, es claro el fomento del conocimiento de la diversidad existente en el país para los currículos de la educación física, dinamizando investigaciones de la pluralidad epistémica que posee cada pueblo indígena, campesino, afro, entre otros.

De igual forma, se indica en estos lineamientos curriculares que:

Colombia es un país en el que la diversidad constituye uno de los rasgos de su identidad que se expresa en multiplicidad de características personales, de culturas, etnias, regiones geográficas, sectores sociales, paisajes urbanos y rurales, en las diferencias de género y de edades. Son también manifestaciones de la diversidad cultural, la tradición y lo actual, lo local y lo global. Al reconocer la diversidad, la Ley General de Educación (Ley 115 de 1994) incluyó las diferentes modalidades de Educación que deben ser tenidas en cuenta en el currículo: educación formal, no formal e informal, educación para personas con limitaciones o capacidades excepcionales, educación para adultos, educación para grupos étnicos, educación campesina y rural, educación para la rehabilitación social. Según las particularidades de la situación unas veces se requerirán currículos especiales y otras, adecuación de procedimientos dentro de currículos generales (MEN, 2000, p. 20).

Se expresa con claridad, en los lineamientos, la necesidad de fomentar diferentes modalidades educacionales en el currículo para la diversidad cultural en 
las instituciones educativas, ya que cada pueblo requiere de un proceso educativo y pedagógico acorde a su cosmovisión o manera de concebir el mundo, en sintonía con las dinámicas socioculturales propias.

Por tal motivo, el currículo debe ser una apuesta de transformación sociocultural flexible y abierta a los cambios culturales de la nación, respetuoso de la diversidad y sustentado en procesos investigativos, que ayuden a superar los antagonismos propios de los currículos establecidos y hegemónicos.

Es pertinente expresar también que, en los lineamientos curriculares, se esboza una diversidad de categorías referentes a la cultura existente en el contexto colombiano, como pluriculturalidad, diversidad, etnicidad, reconocimiento cultural, multiculturalidad e interculturalidad, pero que, por lo ambiguo, que en muchos de los casos resulta, sumado a un desconocimiento efectivo de lo que esto representa, es imposible definir políticas públicas en pro de la dignificación de las culturas en todos los ámbitos educativos del país desde los organismos institucionales.

Por otra parte, en el Plan Decenal del Deporte, la Recreación, la Educación Física y la Actividad Física para el Desarrollo Humano, la Convivencia y la Paz 2009-2019 se encuentran referencias al derecho que tienen todos los pueblos de Colombia a la recreación, a la actividad física y el tiempo libre, sin distingos de edad, sexo, raza, credo, condición política o cultural (Coldeportes, 2009).

Entre los propósitos, resalta promover el desarrollo cultural y social, las expresiones de diversidad y multiculturalidad, respetando las diferencias, particularidades y necesidades culturales. Lo que permitirá fomentar el desarrollo de los pueblos, desde la participación comunitaria, la integración, la democratización y la ética deportiva, para la trasformación social como herramienta para superar el conflicto en el país.

Igualmente, busca contribuir con el fortalecimiento de la rica diversidad y pluriculturalidad como las que están presentes en los contextos educativos universitarios, para que tengan la posibilidad de explorar diferentes modalidades deportivas. Insta, de la misma forma, a promover la inclusión social desde la recreación, a las poblaciones vulnerables, como estrategia para la garantía de los derechos a las poblaciones desplazadas, las negritudes y los indígenas, entre otros. No obstante, no es claro cómo fortalecer las prácticas ancestrales y tradicionales, ya que, en la mayoría de sus páginas hace referencia al deporte desconociendo de esta forma la multiplicidad de prácticas lúdicas con lo cual se acentúa el proceso de aculturación, que dice superar (Coldeportes, 2009).

De otra parte, el documento Orientaciones Pedagógicas para la Educación Física, Recreación y Deporte esboza un importante compendio de pautas que guían el camino formativo en lo conceptual, lo pedagógico y lo didáctico. 
Así plantea el concepto formativo desde el cuerpo, como la condición de posibilidad de ser, estar y actuar en el mundo, mediado por el juego y lo lúdico, como un ejercicio de libertad y creatividad humana, sin una consideración especial respecto a la pluricultural para el campo de la Educación Física (MEN, 2010).

$\mathrm{Al}$ igual que en la serie de lineamientos curriculares, en este tratado, la interculturalidad, la diversidad, la pluriculturalidad y la cultura de los pueblos tienen presencia, pero de forma confusa. De lo que se colige que, aunque se legisle para la cultura de los pueblos, aún perdura la invisibilización y la consecuente vulneración de los derechos, lo que acentúa la represión y subalternización de las culturas y de las comunidades originarias.

Para sintetizar, es necesario analizar a qué se está llamando cultura, socioculturalidad, diversidad, pluricultural en los diversos textos normativos, puesto que su explicitación no es garantía de aplicación real, como tampoco es clara la manera de su abordaje e implementación por parte de las instituciones responsables.

Es preciso problematizar los prefijos que se desprenden de las dimensiones jurídicas de lo intercultural, multicultural, pluricultural o transcultural, ya que estos conceptos invisibilizan y confunden la diversidad social; así se use en políticas públicas, el mismo Estado homogeniza la diversidad cultural sin la posibilidad real de la heterogeneidad.

Para el caso específico de la formación profesional en el campo de la Educación Física, Recreación y Deporte, se requiere pensar en una universidad de pluralidades en la que converjan múltiples voces, tradiciones, posturas, ideologías, conocimientos ancestrales y experiencias, que visibilicen y refortalezcan las distintas maneras de ser, actuar y habitar el cosmos.

Como lo plantea Santiago Castro (2007), hay necesidad de una transculturización del conocimiento como un segundo paso de la transdisciplinariedad, para que haya la posibilidad de que las diferentes formas culturales de conocimiento puedan convivir en el mismo espacio universitario y «entablar diálogos y prácticas articulatorias con aquellos conocimientos que fueron excluidos del mapa moderno de las epistemes por habérseles considerado «míticos», «orgánicos», «supersticiosos» $y$ "pre-racionales» (p. 90).

Esto implica la generación de gestiones y políticas de Estado y de las instituciones educativas que posibiliten recursos y condiciones para llevar a la práctica la interculturalidad en los espacios universitarios, desde la transformación de acciones pedagógicas, como del apoyo para investigaciones profundas a favor de la diversidad cultural y social. 
Es una gran apuesta por la cual hay que luchar para lograr la "pluriversidad transmoderna decolonial futura, cuya producción de conocimiento estará al servicio de un mundo más allá del "sistema-mundo capitalista/patriarcal occidentalocéntrico/ cristianocéntrico moderno/colonial”" (Grosfoguel, 2013, p. 50).

Los pueblos originarios ya vienen logrando reivindicaciones. Se espera la lucha conjunta de la sociedad para lograr la pluriversalidad epistémica en oposición a la universalidad del conocimiento eurocéntrico que equivale a una posición relativista.

\section{Consideraciones Finales}

No obstante que en la Constitución Política de Colombia de 1991 y el marco normativo de la educación del país se encuentra una amplia referencia a la diversidad social y cultural de la nación, el presente estudio llama la atención sobre la escasa presencia de descriptores directos a la interculturalidad y la cultura de los pueblos indígenas en los documentos específicos, como el plan decenal, la serie de lineamientos curriculares, la ley 181(Ley del Deporte) y las orientaciones pedagógicas para la educación física.

Se hace necesario, a partir del campo de la Educación Física, Recreación y Deporte, profundizar la forma cómo desde el Estado se promueve el reconocimiento y respeto a la diversidad, según la ley 397 de 1997, en especial, lo referido a las tradiciones lúdicas, recreativas y artísticas.

En la gran mayoría de los documentos analizados se encontró una variedad de categorías como pluriculturalidad, etnicidad, reconocimiento cultural y multiculturalidad, pero sin mucha claridad de cómo esto debe ser abordado y menos aún, de cómo debe ser representado desde una política pública a favor de la diversidad.

Por último, resulta poco evidente la manera cómo se asume el conocimiento de la diversidad y la pluriculturalidad desde los currículos profesionalizantes, establecido por el documento Serie de lineamientos curriculares en Educación Física, Recreación y Deporte.

Si bien no es parte de este texto por los propósitos fijados para el mismo, desde la investigación, se pudo constatar la ausencia de estas categorías en las mallas curriculares de los programas de formación existentes en Colombia. Esto es que, en materia de diversidad e interculturalidad, se aplica la expresión de uso popular que dice: «del dicho al hecho hay mucho trecho». 


\section{REFERENCIAS BIBLIOGRAFÍCAS}

Bardin, L. (1986). Análisis de contenido. Madrid, España: Akal.

Castro, C. M. (2010). La educación indígena ika, kankuama, nasa, wayúu y mokaná fortalecen la interculturalidad en Colombia. Revista Educación y Humanismo, 12(19), 148-176.

Castro, S. (2007). Descolonizar la universidad. La hybris del punto cero y el dialogo de saberes. En S. Castro y R. Grosfoguel (eds.), El giro decolonial. Reflexiones para una diversidad epistémica más allá del capitalismo global (pp. 79-91). Bogotá: Iesco-Pensar-Siglo del Hombre Editores.

Coldeportes Nacional (2009). Plan Nacional del Deporte. Bogotá.

Congreso de Colombia (06 de marzo de 2014). Ley de Transparencia y del Derecho de Acceso a la Información Púbica Nacional [Ley 1712 de 2014]. Recuperado de http://www.mintic.gov.co/portal/604/articles-7147_documento.pdf

Congreso de Colombia (07 de agosto de 1997). Ley cultura, fomentos y estímulos a la cultura, se crea el Ministerio de la Cultura y se trasladan algunas dependencias [Ley 397 de 1997] DO: Recuperado de file://C:/Users/ SAUL/Downloads/Ley\%20397\%20de\%201997.pdf

Congreso de Colombia (28 de diciembre de 1992). Ley de Educación Superior [Ley 30 de 1992]. DO: 40700. Recuperado el 20 de agosto de 2016 de http://www.alcaldiabogota.gov.co/sisjur/normas/Normal.jsp?i=253

Congreso de Colombia (8 de febrero de 1994). Ley General de Educación [Ley 115 de 1994]. DO: 41.214. Recuperado el 20 de agosto de 2016) de http/ www.unal.edu.co/secretaria/ normas/ex/L0115_94.pdf

Congreso de Colombia (18 de enero de 1995). Disposiciones para el fomento del deporte, la recreación, el aprovechamiento del tiempo libre y la Educación Física y creación del Sistema Nacional del Deporte [Ley 181 de 1995]. Recuperado el 20 de agosto de 2016 de https://www.mineducacion.gov. co/1621/articles-85919_archivo_pdf.pdf

Constitución Politica de Colombia de 1991 (2016). Bogotá, Colombia: Ed. Unión Ltda.

Corona, S. y Kaltmeier, O. (2012). En diálogo. Metodologías horizontales en ciencias sociales y culturales. Barcelona, España: Gedisa.

Delgado, J. (1998). Métodos y técnicas cualitativas de investigación en ciencias sociales. Madrid, España: Síntesis.

Geertz, C. (1989). El impacto del concepto de cultura en el concepto del hombre. En C. Geertz, La interpretación de las culturas (pp. 43-59). Barcelona: Gedisa. 
Grosfoguel, R. (2013). Racismo/sexismo epistémico, universidades occidentalizadas y los cuatro genocidios/epistemicidios del largo siglo XVI. Tabula Rasa, 19, 31-58. https://doi.org/10.25058/20112742.153

López, L. E. (2004). Interculturalidad y educación superior: el caso de la formación docente. Educación, 13(24), 1-9.

Maura, V. G. y Tirados, R. M. (2008). Competencias genéricas y formación profesional: un análisis desde la docencia universitaria. Revista Iberoamericana de Educación, (47), 185-209.

Ministerio de Educación Nacional (2000). Serie lineamientos curriculares. Educación Física, Recreación y Deporte. Recuperado de http://www. mineducacion.gov.co/1759/articles-339975_recurso_10.pdf

Ministerio de Educación Nacional (2010). Orientaciones pedagógicas para la Educación Física, Recreación y Deporte. Recuperado de http://www. mineducacion.gov.co/1759/articles340033_archivo_pdf_Orientaciones_ EduFisica_Rec_Deporte.pdf

Molina-Bedoya, V. A. (2012). Prácticas socioculturales de resistencia en la comunidad indígena nasa. Fiestas, celebraciones y encuentros colectivos. Pensar a Prática, 15(1), 71-87.

Ruiz, J. (1999). Metodología de la investigación cualitativa. Bilbao, España: Universidad de Deusto.

Sánchez, E., Enrique, M., Benjumea, S., Rodríguez, I. y Nieto, B. (2003). Los pueblos indígenas en Colombia: derechos, politicas y desafios. Bogotá: Unicef.

Villodre, B. y del Mar, M. (2012). Pluriculturalidad, multiculturalidad e interculturalidad, conocimientos necesarios para la labor docente. Hekademos, 1(11), 67-76. 